\title{
Cooperation of a Photovoltaic Power Plant with a Battery Energy Storage System
}

\author{
Martin Vojtek $^{1 *}$, Michal Kolcun ${ }^{2}$, Zsolt Čonka ${ }^{3}$, Miroslav Mikita ${ }^{4}$ \\ ${ }^{1-4}$ Technical University of Košice
}

\begin{abstract}
This paper deals with modelling of a photovoltaic power plant in combination with a battery energy storage system and their cooperation in order to better renewable energy utilization at local level. In this paper, the model of grid on a hybrid system that is formed by the battery energy storage system, a photovoltaic power plant, a utility grid and a small commercial load is proposed. Battery energy storage system based on lithium ion technology is connected by a DC-DC bidirectional power converter to the DC bus together with a photovoltaic power plant. Avltage source converter is used for conversion of $\mathrm{DC}$ to $\mathrm{AC}$ power. Utility grid and commercial load are connected to the AC side. Modeling of a hybrid system and simulation of the system's behaviour during a random day of the year was performed in Matlab/Simulink environment employing SimPowerSystems toolbox. The results show the cooperation of the battery energy storage system and the photovoltaic power plant using system control in order to satisfy load requirements.
\end{abstract}

Keywords - Battery, control, cooperation, energy storage, li-ion, photovoltaic, Simulink.

\section{INTRODUCTION}

The share of renewable energy sources in total generation capacity of the European Union continuously increases. This is happening because of the efforts to decrease carbon dioxide and other emission produced by power plants combusting fossil fuels. There are also some problems with protection of nuclear power plants against external damaging effects, therefore some countries have decided to stop their operation and replace them gradually.

The huge penetration of distributed generation based on renewable energy sources into power systems brings some concerns from the viewpoint of maintaining the existing security, quality and reliability of electricity supply [1]. These concerns have a reason arising from the nature of most renewable energy sources types. They have a varying, intermittent and hardly predictable power output, which varies according to environmental conditions such as solar irradiance or wind speed. In addition, energy price and load level are also varying in time [2]. The residual load as the difference between electricity demand and must-run generation of renewable energy sources will become highly volatile. To avoid a system blackout due to an insufficient technical and economical flexibility of conventional power plants, storage technologies are becoming more and more discussed as one of the main means to ensure the security of electricity supply in future [4].

Energy storage systems are one of the solutions necessary to integrate renewable energy generation to the existing power networks [4]. By their mutual cooperation mainly with photovoltaic power plants or wind farms within hybrid systems they can achieve powerful features. Control functions and integration of renewable energy sources and energy storages are provided by converters, which can also act as an interface between the DC and AC power. Nowadays, development of power electronics has resulted in more powerful and responsive power converters, which allows controlling complex distributed generators and various functions of energy storage management system [6]-[8].

Photovoltaic power plants in combination with energy storage form a significant part of distributed generators, since with energy storage a solar system becomes a stable energy source, which can be dispatched at request [7], [8]. Together with power electronics, they can provide flexible energy management solutions involving time shifting, improving the power quality, end-user overall bill management, ramping functions, and others. For example, in [8], Yukita et al. present a study of power quality parameters in a hybrid distributed generator with and without battery-based energy storage. It was clearly showed that voltage and frequency was improved in the case of battery utilization. Thanks to rapid development of batteries, battery energy storage has recently begun to be utilized in a wide range of applications, such as frequency regulation, grid stabilization, transmission loss reduction, diminished congestion, spinning reserve, peak shaving, load leveling, uninterruptible power sources, grid services, electric vehicle charging stations, and others. Several control strategies and configurations of hybrid photovoltaic distributed generators have been proposed by many authors, and they are further described in [8], [10]-[12].

This paper describes modeling of a photovoltaic-battery hybrid system and its configuration to achieve a stable and controllable power output in order to satisfy the load requirements independent on weather conditions. By presented approach it is possible to change the variable and intermittent power generation, typical for photovoltaic power plants, to generation of a constant or actually required power. In the next section, every part and control of the system is described in

${ }^{*}$ Corresponding author.

E-mail address: martin.vojtek@tuke.sk 
detail. Section III deals with the simulation of the proposed system and highlights the results of the simulated scenarios.

\section{SYSTEM MODELING}

A hybrid photovoltaic-battery generation system was physically modelled using Matlab/Simulink software employing SimPowerSystems simulation toolbox. It consists of four basic parts, while all of them represent independent functional units, namely, photovoltaic power plant, battery energy storage system, utility grid, and dynamic load (Fig. 1).

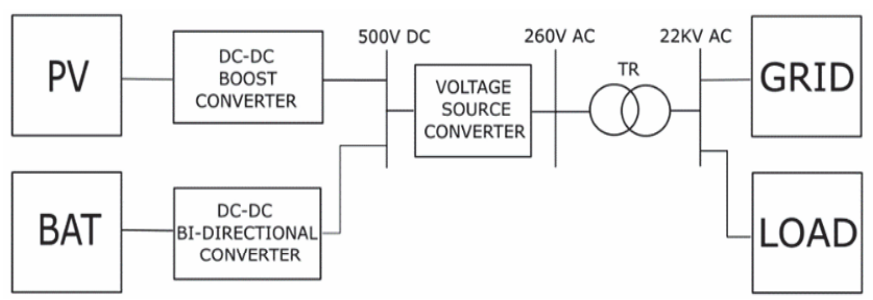

Fig. 1. Topology of the modelled system.

The proposed system can be divided into the DC and AC side, which are interfaced by the voltage source converter (VSC). The photovoltaic power plant and battery energy storage are connected to a DC bus of the system by DC-DC converters. VSC converts DC to AC power. Utility grid and static load are connected directly to the AC side.

\section{A. Photovoltaic Power Plant}

Power generation part of the photovoltaic plant is PV array, and it is modeled by one diode equivalent circuit. The mathematical description of the model is further analyzed in [13] and [14].

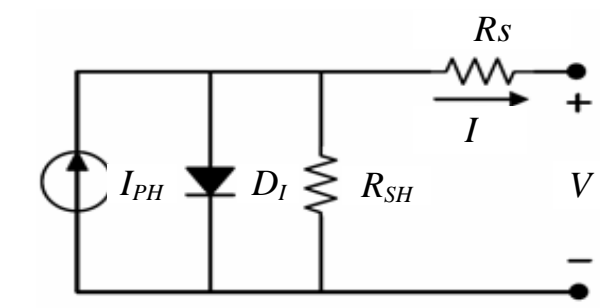

Fig. 2. General equivalent circuit of a photovoltaic cell.

The whole generation unit consists of 66 parallel connected strings, while each has five SPR-305-WHT modules by SunPower Company connected into series. Basic parameters of the module under standard test conditions are presented in Table I.

TABLE I

MOdUlE SPECIFICATION UNDER STANDARD TEST CONDITIONS

\begin{tabular}{|l|c|}
\hline Parameter & Value \\
\hline Open circuit voltage (V) & 62.4 \\
\hline Short circuit current (A) & 5.96 \\
\hline Number of series connected cells per module $N_{S}(-)$ & 96 \\
\hline Power (W) & 305 \\
\hline
\end{tabular}

This configuration results in 330 modules, which creates a photovoltaic plant with nominal output power of $100.7 \mathrm{~kW}$ and voltage of $273.5 \mathrm{~V}$ at the maximum power point. PV arrays are connected to an average model of DC-DC boost converter, which is controlled by the maximum power point tracking (MPPT) algorithm based on the perturb and observe technique. This algorithm tracks the maximum power point by varying the duty cycle of the converter. Duty cycle changes affect the voltage of PV array, and it is changing according to extract maximum power from the array at each time. Perturb and observe and other MPPT techniques are further described in [15]. Besides, the DC-DC converter boosts the actual voltage at the maximum power point to constant reference value of $500 \mathrm{~V}$.

\section{B. Battery Energy Storage System (BESS)}

BESS consists of lithium-ion batteries and bidirectional DCDC converter. A battery block from Simulink library was used. It implements a generic battery model. Nominal voltage and discharge current of the batteries is $260 \mathrm{~V}, 260$ A. Nominal output power of $67.7 \mathrm{~kW}$ is obtained by these values. Rated capacity is $3000 \mathrm{Ah}$. The number of cells and their connection inside the battery container were neglected. It was modeled as a one large-capacity battery. Typical discharge characteristic is shown in Fig. 3.

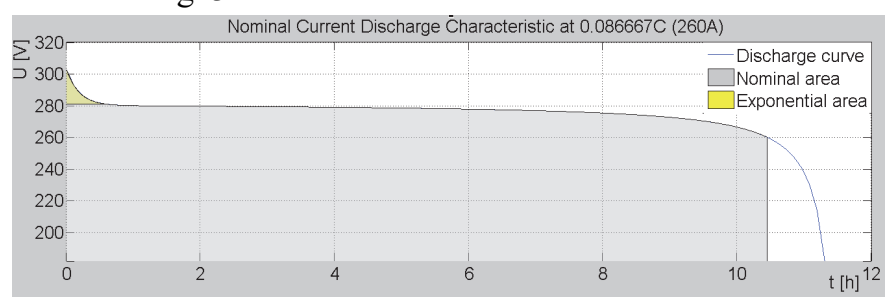

Fig. 3. Nominal current discharge characteristic at $0.195 \mathrm{C}$.

The bidirectional DC-DC converter allows the current to flow in both directions. It is used for battery charging or discharging according to the actual power request. The required power is obtained by a simple equation, which describes active power balance between the production and consumption side:

$$
P_{\text {load }}+\Delta P=P_{\mathrm{pv}}+P_{\text {batt }}
$$

Battery power $P_{\text {batt }}$ is the required power from the battery. $P_{\mathrm{pv}}$ is the DC power generated by the photovoltaic array, and $\Delta P$ reflects power losses in power electronic of converters, a coupling transformer, and LC filter. The result of this equation is fed to bidirectional DC-DC converter as a required power command. The converter is based on the inductor and MOSFET transistors in both directions. For example, when the converter obtains a positive value of the required power, it means that the battery is discharging. In this case, current is calculated from power command. It is subtracted by actual current and then this error is fed into the PID regulator. The output of the PID is compared with the carrier signal, and when it is higher or equal, the firing pulse is sent to the gate of MOSFET. At this time, it causes that the transistor acts as a small resistance and the current can flow from the battery. By this simple logic and fast transistors switching in combination with inductor, it is 
achieved that the current can flow in the required direction with the requested value according to the power commands.

\section{Utility Grid}

Utility grid is modeled as a $22 \mathrm{kV}$ medium-voltage distribution feeder connected to a transformer. The feeder consists of couple lines and loads. The other side of the transformer is connected to the equivalent of a $110 \mathrm{kV}$ highvoltage distribution grid with a 2500 MVA three-phase shortcircuit apparent power.

Utility grid serves as the main source when simultaneously the power generated by photovoltaic and the battery power is not available or as a complementary source in the case when the power generated by a hybrid system is not sufficient to satisfy the load. It is also used for compensation of small- and shortduration power unbalance between the power generated and the power needed by the load.

\section{Dynamic AC Load}

The load is connected at the AC side of the system and it is modeled by the dynamic load block from Simulink library. The nominal active power of the load is $60 \mathrm{~kW}$. This value is changing in time according to a signal, which describes a typical daily load curve of a small commercial customer for a simulated day.

\section{SiMULATION AND RESULTS}

A random day in the year 2015 was chosen and simulated 20th September - to verify the validation of the model. It was a partly cloudy day. Solar irradiation (Fig. 4) and load curve (Fig. 5) during this day were implemented as inputs into the described model, and behavior of the system was observed. Simulation time was 86400 seconds, and an ode45 (dormandprince) solver was used with a $5 \times 10^{-4} \mathrm{~s}$ sample time for control part, and $2.5 \times 10^{-4} \mathrm{~s}$ for power system components.

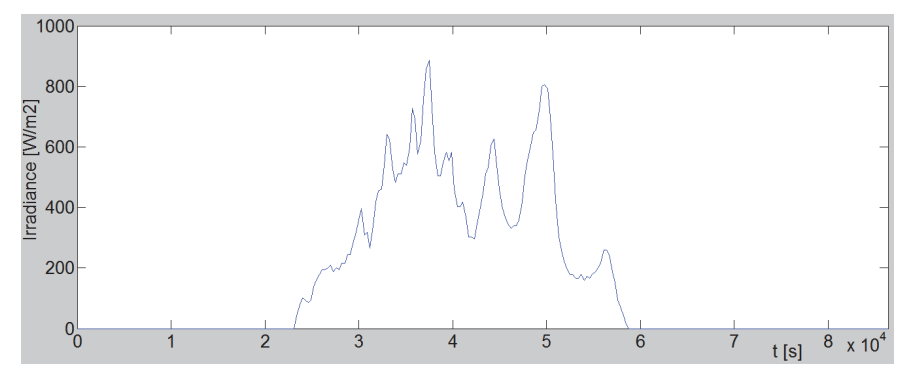

Fig. 4. Simulated solar irradiance.

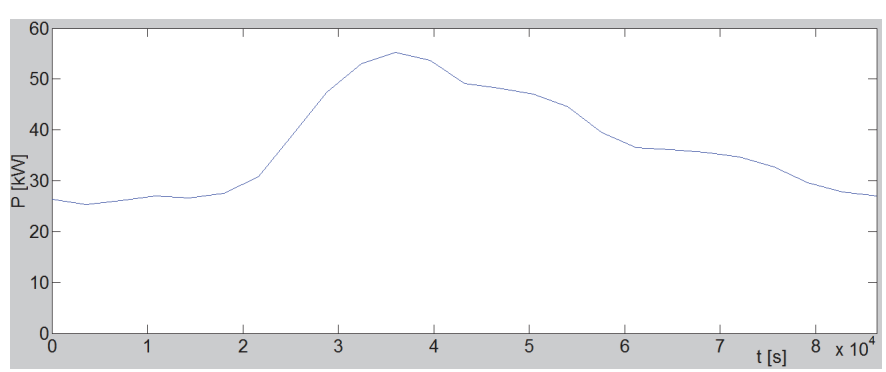

Fig. 5. Simulated load curve.
Fig. 6 demonstrates the active power generated by the photovoltaic power plant. It can be seen that it is changing according to solar irradiance. Peaks and hollows of power generation occur many times during the day, because of the cloudy weather.

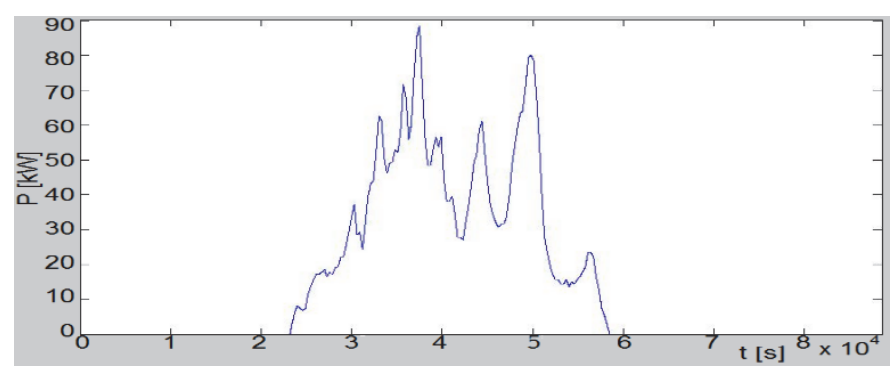

Fig. 6. Power delivered by the photovoltaic power plant.

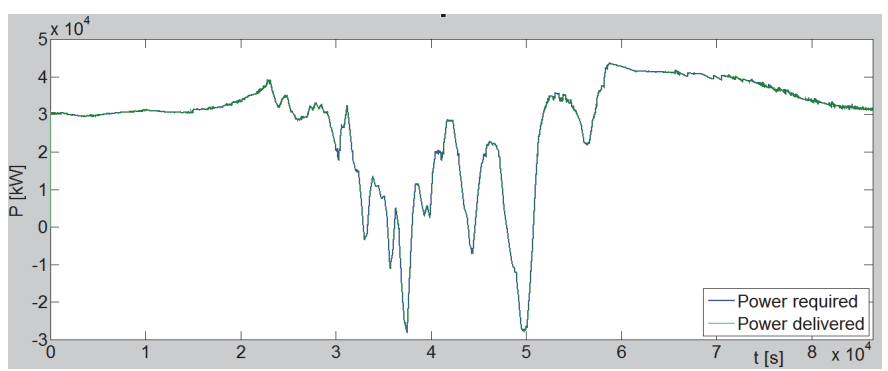

Fig. 7. Battery required and delivered power.

The battery reacts on the photovoltaic power generation and tries to deliver such amount of power that is needed to satisfy the load and cover the power losses in every time of the day. This is happening according to power commands, counted based on the equation (1). This process is described in Fig. $7-$ the power required represents the counted power command, and the power delivered is veritable power delivered by the battery. The positive values of the battery power represent battery discharging, and vice versa.

It was assumed that at the beginning of simulation, the battery was fully charged. It means that the battery state of charge (SOC) equaled $90 \%$. During the simulated day, there was not enough power generated from the photovoltaic power plant, therefore the battery was discharged almost all day long. This caused decrease in SOC slightly above $10 \%$, which is its minimal value (Fig. 8). After exceeding this value, the customer must be supplied only from the utility grid or both the utility grid and the photovoltaic power.

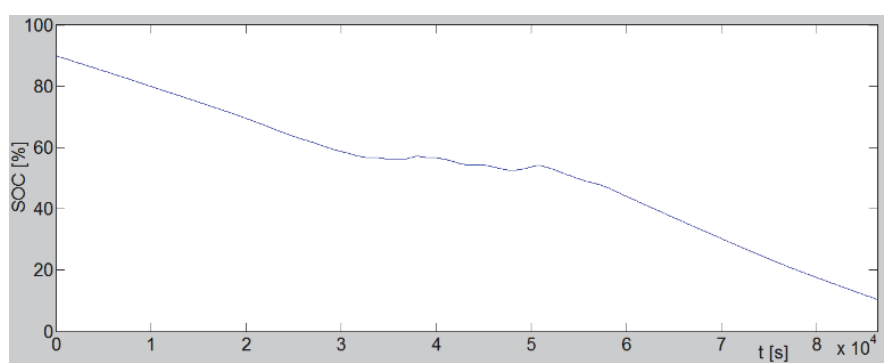

Fig. 8. Battery state of charge. 
Also the voltage and current of the battery were observed during the whole simulation. Voltage was decreasing according to discharge characteristic (Fig. 9), and current was following the current calculated from the power commands (Fig. 10).

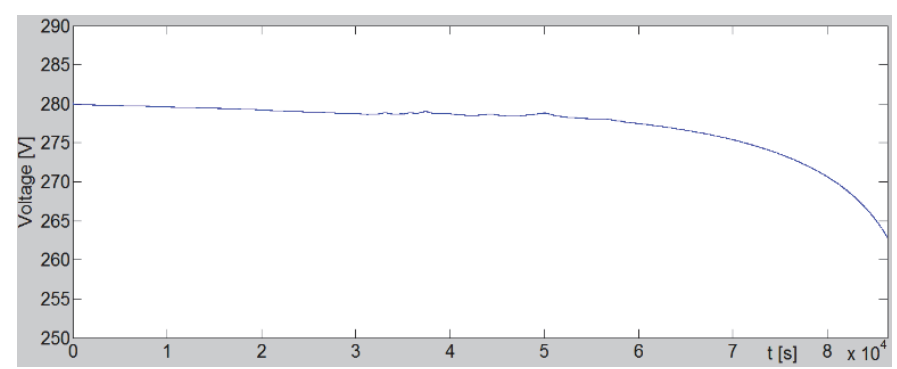

Fig. 9. Battery voltage.

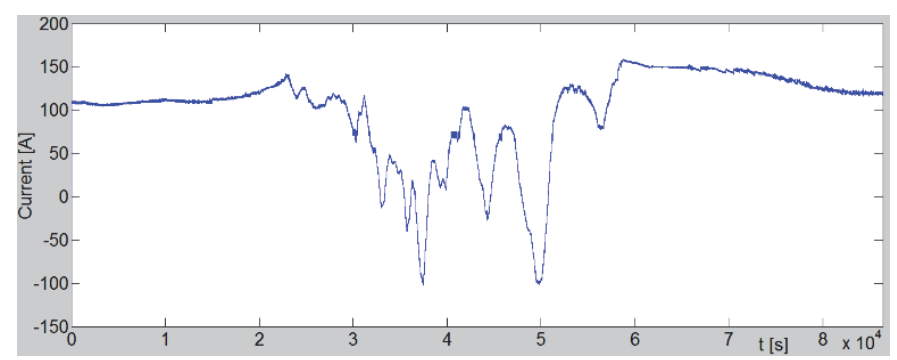

Fig. 10. Battery current.

The resulting power delivered by the photovoltaic power plant in combination with battery into the AC bus, where the dynamic load is connected, is shown in Fig. 11. It is marked with a blue line and follows the green one, which represents the load power demand.

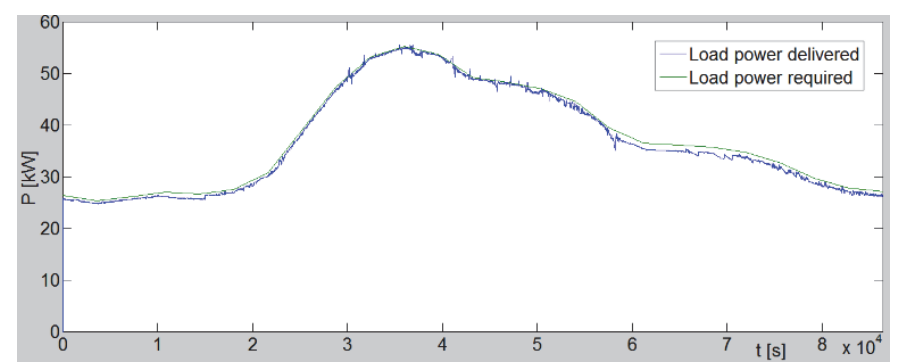

Fig. 11. Load required and delivered power.

Progressions of the photovoltaic power generated, total power delivered to the AC bus by the hybrid system, battery power generation, and consumption and power required by the dynamic load show the behavior of the simulated system. This power balance is demonstrated in Fig. 12.

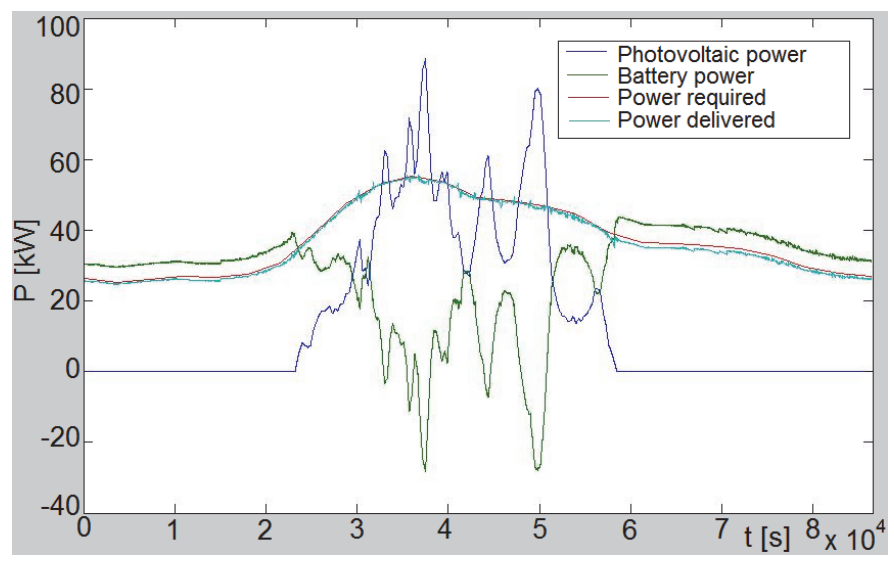

Fig. 12. Power balance of the system.

\section{CONCLUSION}

In this paper, modeling of a hybrid system that consists of a photovoltaic power plant in combination with a battery energy storage system, load and utility grid was proposed. Each main model part and its implementation were also described, and random day simulation intended to confirm the validity of the model was done.

During the simulated day, battery state of charge decreased to $10 \%$, therefore the battery was discharged - there was not enough power produced by the photovoltaic plant to satisfy the load and the difference was supplied by the battery power.

The behavior of the system showed that it was working properly. The power delivered to the AC bus by the hybrid system followed the power required by load; however, a slight oscillation around the reference value was noted. This might have been caused by the ripple current of the bidirectional DCDC converter and also by the perturb and observe algorithm. Improvement of these issues will be the subject of future study.

\section{ACKNOWLEDGMENT}

This work was supported by the Slovak Research Agency No. VEGA 2/0071/16 project. 


\section{REFERENCES}

[1] P. J. Hall and E. J. Bain, "Energy storage technologies and electricity generation,” Energy Policy, vol. 36, 2008, pp. 4352-4355.

[2] http://dx.doi.org/10.1016/j.enpol.2008.09.037

[3] K. L. Dinh and Y. Hayashi, "Coordinated BESS control for improving voltage stability of a PV-supplied microgrid," in 48th Int. Universities Power Engineering Conf., UPEC, Sept. 2-5, 2013, pp. 1-6. http://dx.doi.org/10.1109/UPEC.2013.6715027

[4] S. Sieling, J. Welsch and H.-J. Allelein, "Modeling and evaluation of combined photovoltaic-battery systems in the decentralized German power generation," in Int. conf. on Renewable Energy Research and Application, ICRERA, Oct. 19-22, 2014, pp. 770-775. http://dx.doi.org/10.1109/ICRERA.2014.7016489

[5] N. Garimella and N. C. Nair, "Assessment of battery energy storage systems for small-scale renewable energy integration," in TENCON 2009 -IEEE Region 10 Conf., Jan. 23-26, 2009, pp. 1-6. http://dx.doi.org/10.1109/TENCON.2009.5395831

[6] Ch. K. Sao, P. W. Lehn, "Control and power management of converter fed micro-grids," IEEE Trans. on power syst., 2008, pp. 1088-1098. http://dx.doi.org/10.1109/TPWRS.2008.922232

[7] ESA - Energy Storage Association, Washington, USA, 2016. [Online]. Available: www.energystorage.org

[8] L. Baoqi, et al., "An integrated control strategy of PV-battery hybrid systems," in Electron. and Appl. Conf. and Exposition, PEAC, Nov. 5-8, 2014, pp. 419-422.

[9] K. Yukita, et al., "A study of electric power quality using storage system in distributed generation," in 9th Int. Conf. Electrical Power Quality and Utilisation, EPQU, Oct. 9-11, 2007, pp. 1-4. http://dx.doi.org/10.1109/epqu.2007.4424142

[10] X. Li, D. Hui and X. Lai, "Battery Energy Storage Station (BESS)-Based Smoothing Control of Photovoltaic (PV) and Wind Power Generation Fluctuations," IEEE Trans. Sustain. Energy, vol. 4, no. 2, April 2013, pp. 464-473. http://dx.doi.org/10.1109/TSTE.2013.2247428

[11] J. F. Reynaud, et al., "A novel distributed photovoltaic power architecture using advanced Li-ion batteries," in 14th Int. Conf. Power Electronics and Motion Control, EPE/PEMC, Sept. 6-8, 2010, pp. S9-6-S9-12. http://dx.doi.org/10.1109/epepemc.2010.5606548

[12] T. V. Thang, et al., "Flexible System Architecture of Stand-Alone PV Power Generation With Energy Storage Device," Energy Conversion, vol. 30, no. 4, Dec. 2015, pp. 1386-1396. http://dx.doi.org/10.1109/TEC.2015.2429145

[13] A. Islam and M. Chowdhury, "A Simulink based generalized model of PV cell/array," in 3rd Int. Conf. Developments in Renewable Energy Technology, ICDRET, May 29-31, 2014, pp. 1-5. http://dx.doi.org/10.1109/icdret.2014.6861683

[14] S. Said, et al., "A Matlab/Simulink-Based Photovoltaic Array Model Employing SimPowerSystems Toolbox," J. of Energy and Power Eng., vol. 6, Dec. 2012, pp. 1965-1975.

[15] M. A. G. de Brito, et al., "Comparative analysis of MPPT techniques for PV applications," in Int. Conf. on Clean Elect. Power, ICCEP, June 14 16, 2011, pp. 99-104. http://dx.doi.org/10.1109/ICCEP.2011.6036361 